\title{
Using role play and explicit strategy instruction to improve first-year students' academic reading proficiency
}

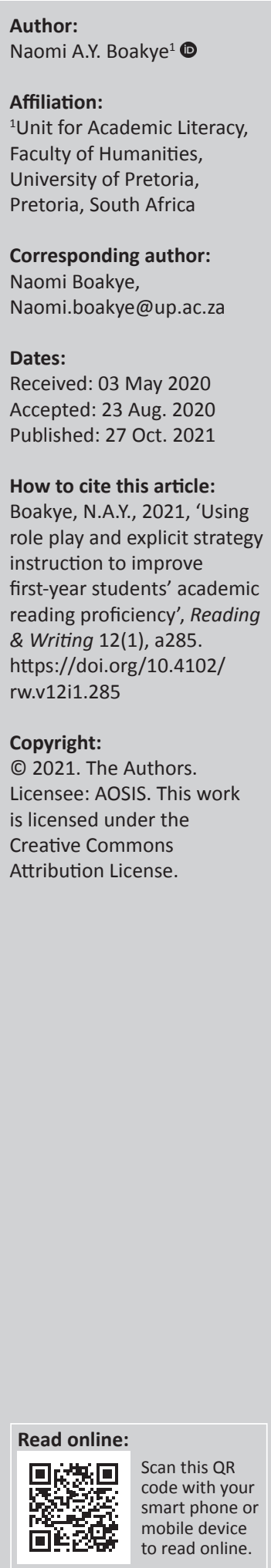

Background: Many first-year students find the reading of academic texts to be challenging and overwhelming. In particular, first-year students studying sociology at the South African institution where the study was conducted complain of comprehension challenges. This may be due to the presence of numerous theoretical and abstract concepts in sociology texts, which have to be unpacked in order to gain a greater understanding of social phenomena. A high level of reading proficiency is required in the reading of sociology texts; however, some students are poor readers and find it difficult to cope.

Objectives: The article reports on a support programme aimed at improving first-year sociology students' academic reading proficiency.

Method: In addition to explicit strategy instruction, which has been used by many researchers to improve reading comprehension, role play was introduced to the reading of sociology texts during tutorials in order to promote deep reading and improve comprehension. Pre-tests and post-tests, together with closed-ended and open-ended questionnaires, were used to determine the efficacy of the intervention. The tests were analysed using t-tests, and the questionnaires were analysed using descriptive statistics for the closed-ended section and content analysis for the open-ended questions.

Results: The findings showed that a significant number of students had improved their reading proficiency and reported both cognitive and affective benefits.

Conclusion: Recommendations are made in relation to the use of role play in addition to explicit strategy instruction in order to maximise the improvement of students' academic reading ability.

Keywords: role play; strategy instruction; reading proficiency; cognitive and affective reading strategies; first-year sociology students.

\section{Introduction}

Learning, studying and engaging in academic reading and writing activities at the tertiary level seems to be quite overwhelming for some students. Whereas learners at the school level are taught and guided closely, at the tertiary level, students are given more autonomy and are required to study and pursue their academic activities - which are mainly reading and writing more independently. In addition, the quantity and complexity of the texts they are required to read at the tertiary level and the level of writing required of them can be overwhelming for students at first-year level. This could be due to the fact that the school system did not place such high demands on them (Boakye \& Linden 2018; Boakye \& Mai 2016), and also because they are no longer closely guided and monitored by their teachers and parents. Furthermore, students are introduced to highly technical words in their content subjects, which makes reading in these subjects daunting and effortful for some of them.

The Sociology 110 module offered at the South African institution where the study was conducted, for example, requires students to read texts by authors such as Karl Marx, Max Webber and Emile Durkheim, which may not be easily understood by some first-year students. According to Roberts and Roberts (2008), some first-year sociology students do not read their assigned texts due to the quantity and complexity of the assigned readings, as well as the difficult vocabulary, much of which consists of technical, subject-specific words that are not familiar to the students (Boakye \& Mai 2016). These high academic reading demands and writing expectations of first-year students mean that they need to be proficient readers in order to be successful in their academic activities. 
The situation is more complex for students from low socioeconomic status backgrounds who have not had adequate exposure to texts at home or at school and are disadvantaged in their reading ability, and consequently in their academic performance (Taylor \& Yu 2009).

Reading instruction has therefore become an important avenue to improve students' reading proficiency and academic performance. Teaching students reading strategies and making them aware of efficient reading techniques have constituted an important approach to improving their reading ability. The approach of many support programmes has been to teach cognitive and metacognitive reading strategies, considering that the use of appropriate reading strategies results in reading comprehension (Aghaie \& Zhang 2012; Anderson 1991; Bruen 2017; Cohen 2011; Graesser 2007; Mokhtari \& Sheorey 2002; Oxford 1990, 2011). However, reading efficiency may be limited without high affective levels and the ability to transfer skills. This study extends the teaching of strategies to include role play through which students engage in the discussion of sociology texts to increase motivation and improve strategy use. As explained by Eghlidi, Abdorrahimzadeh and Sorahi (2014), students who engage in problem-solving activities increase their reading comprehension. Ilustre (2011) found that of the three subscales of metacognitive reading strategies used in her study (global, support and problem-solving), only problem-solving strategies correlated positively with text comprehension. Students who reported to be using problemsolving reading strategies obtained relatively higher scores in the reading tasks (Ilustre 2011). Thus, she concludes that problem-solving reading strategies contribute to text understanding (Ilustre 2011). The role play technique included in the reading programme was to enable students to apply cognitive and metacognitive strategies they had been taught in class to their assigned roles to solve comprehension problems and to increase their affective reading levels.

In addition, role play as a teaching technique has been found to increase motivation, interest and engagement (Erturk 2015; Samsibar \& Naro 2018; Science and Engineering Research Council [SERC] 2018). For students from low socio-economic status backgrounds who have had limited exposure to texts and may therefore have low affective levels and poor cognitive and metacognitive strategy use, this cognitive-affective approach is even more important for improving their reading comprehension. Such students usually face comprehension challenges. However, the combined approach has not been used in a focused way in reading programmes. The study therefore sought to improve first-year students' reading proficiency using a combined approach of cognitive strategies and role play discussions.

The following questions were therefore posed for the study:

- To what extent will an intervention of reading comprehension strategy instruction through role play improve students' reading of academic texts?
- Will the use of role play in reading comprehension strategy instruction influence students' affective reading levels and strategy use?

- What are students' opinions on the use of role play in a reading comprehension strategy instruction?

\section{Literature review Reading strategies and reading comprehension}

Various factors that influence reading proficiency have been identified by researchers, but of the four major factors that need to be considered (the reader, the text, the goal and the strategies), strategies used by learners for comprehension seem to be the single most important (Grabe \& Stoller 2011; McNamara 2007). Reading strategies are defined by Brown (2007:119) as the 'specific methods of approaching a problem or task'. Karami (2008) takes this further and defines reading strategies as the conscious, internally variable psychological techniques aimed at improving the effectiveness of, or compensating for the breakdowns in, reading comprehension on specific reading tasks and in specific contexts. He highlights as important the following aspects of reading strategies: conscious, subject to change, used to address problems, context-dependent, used to improve reading performance, and used to address comprehension breakdown. Pani (2004), from another perspective, defines reading strategies as 'the mental operations involved when readers approach a text effectively to make sense of what they read'. He opines that ' $[\mathrm{g}] \mathrm{ood}$ readers apply more strategies more frequently ... and more effectively than poor readers' (Pani 2004:356). Consequently, the use of reading strategies for comprehension differentiates poor readers from good readers (Brown 2001; Graesser 2007).

Researchers such as Chamot (2005), Alderson (2000) and Grabe (2008) point out that the distinguishing feature of reading strategies is that they are utilised consciously for comprehension. These cognitive and metacognitive reading strategies are to be used efficiently for comprehension to occur. Cognitive strategies involve activation of background knowledge, summarisation, questioning and guessing meaning from context, among others. Metacognitive strategies, on the other hand, include comprehension monitoring, repair of comprehension breakdown, and other affective influencing strategies such as matching comprehension output to reader goals and motivation (Grabe \& Stoller 2011). They both involve the specific reading context, monitoring, and evaluating the success of the reading process, and are important for comprehension. As explained by Karami (2008) and other reading researchers such as Anderson (1991), Brown (2007) and Oxford (2011), the impact of these strategies on reading is conceived to be of crucial importance in any act of reading. For Brown, 'reading comprehension is a matter of developing 10 appropriate and efficient comprehension strategies' (Brown 2007:306). He identifies these strategies as follows: identifying the purpose in reading; using graphemic rules and patterns to aid in bottom-up reading, using different silent reading techniques for relatively rapid reading, skimming the text for 
main ideas, scanning the text for specific information, using semantic mapping or clustering, guessing when you are not certain, analysing vocabulary, distinguishing between literal and implied meanings, and capitalising on discourse markers to process relationships.

Lau (2006), on the other hand, cites five characteristics of poor readers:

1. They do not know how to construct the main ideas and macrostructure of the texts.

2. They are not familiar with the text structure and do not make use of it to organise the main ideas.

3. They have little prior knowledge and do not know how to activate their knowledge to facilitate text comprehension.

4. They have difficulties in drawing inferences to achieve an in-depth understanding of the texts.

5. They lack metacognitive ability, are not aware of the problems that emerge during reading and do not know how to monitor their reading process.

These characteristics of poor readers were found in Pretorius' (2000) study of first-year psychology and sociology students. She found that the majority of the students could not draw inferences to obtain an understanding of the texts and that poor readers from low socio-economic status backgrounds lacked the metacognitive ability to evaluate their comprehension and address gaps accordingly. Poor readers rated their reading ability as better than it really was, as they lacked the metacognitive ability to identify their lack of knowledge (Pretorius 2000). Thus, instruction on cognitive and metacognitive strategies would help improve students' use of strategies and awareness or the lack thereof.

Various empirical investigations have been conducted on the benefits of reading strategy instruction. Wright and Brown (2006) investigated the impact of explicit strategy instruction on the reading comprehension of students of Spanish or French as a foreign language. The authors concluded that although the results indicated that the participants' awareness of some strategies and their ability to reflect upon their reading did increase, other strategies seemed more difficult to acquire. They also pointed out that some students faced difficulties in acquiring complex strategies. The fact that some students found some strategies challenging even after strategy instruction indicates that the teaching of strategies alone may not provide optimal benefits.

The use of strategies after they have been learned is influenced by various factors. For example, it is claimed that there is a close relationship between strategy use and motivation or the goal of reading. In other words, students' use of appropriate reading strategies is influenced by their level of motivation (Guthrie \& Wigfield 2000). The higher the motivation and the more important the goal, the more learners utilise appropriate and correct strategies (He 2008; Wigfield et al. 2014). He (2008) investigated the effect of the goal of reading and motivation on the students' utilisation of strategies. The results indicated that the participants with stronger goals generally performed better in the use of strategies and in reading than those with the same proficiency levels but weaker goals and motivation for reading.

Thus, although the literature indicates enormous benefits to the use of strategies for efficient reading, there are other factors, such as affect operationalised as the goal of reading, reading motivation, engagement and reading self-efficacy, among others, that are of equal importance. Reading motivation is an affective stance that refers to an individual's personal goals, values and beliefs with regard to the topics, processes and outcomes of reading (Guthrie \& Wigfield 2000). Reading motivation captures the individual's thoughts and feelings, whereas reading engagement refers to the individual's actual involvement in reading, which is reflected in behaviour, affect or cognition (Guthrie, Wigfield \& You 2012). Reading self-efficacy refers to students' expectation about their own achievement of a reading task and the confidence they have in being able to successfully complete a reading task (Ferrara 2005; Schiefele et al. 2012). Research has shown that students with high reading self-efficacy levels are generally active and more successful readers than students with low self-efficacy (Schiefele et al. 2012).

These affective factors of motivation and self-efficacy are also involved in the application of strategies. Motivated students tend to have high self-efficacy and use appropriate strategies to achieve better comprehension of texts (Yang et al. 2018). Barber and Lutz Klauda (2020), reflect on reports by OECD (2010), and Scheifele et al. (2012) to conclude from their studies that across grade levels as well as ethnic and cultural backgrounds, motivated students show better reading comprehension, higher self-efficacy and general reading achievement. There is therefore a need to extend the teaching of strategies to include techniques such as role-play to increase motivation and self-efficacy in order to maximise the use of strategies to achieve comprehension and improve reading proficiency.

\section{Role play as a teaching technique}

Role play is the practice of having students take on specific roles and act them out in a case-based scenario for the purpose of learning course content or understanding complex or ambiguous texts (Suobere \& Eniekenemi 2017). This teaching technique allows students to explore realistic situations by interacting with their peers in a managed way in order to gain experience and try different reading strategies in a supportive environment (Glover 2014; Budden 2006). Role play could involve dramatisation, simulation, games or demonstrations of real-life situations on any topic (Erturk 2015:1). As a teaching technique, it is perceived as an excellent tool for engaging students and allowing them to interact with their peers as they try to complete the reading task assigned to them in their specific roles. Using role play as a teaching technique enables students to become more engaged, as they respond to the text from the perspective of their assigned role. A SERC document lists several benefits of role play as a teaching technique (SERC 2018). For example, role play allows students to apply content in a relevant, real-world 
context and enables them to break away from their normal self-imposed limitations or boundaries. In addition, students can think beyond the confines of the classroom setting and see the relevance of the content for handling real-world situations. Another advantage of role play is that it enables the instructor and students to receive immediate feedback regarding students' understanding of the content. Furthermore, this teaching technique enables students to engage in higher-order thinking and learning of content in a deeper way (SERC 2018). A typical benefit of role play is that students claim to remember their role in these scenarios and the ensuing discussion long after the semester has ended (SERC 2018).

Researchers who study role play such as Samsibar and Naro (2018), Erturk (2015), Glover (2014), and Chesler and Fox (1966) recommend that steps should be followed when engaging students in role play. The SERC document provides three basic steps: the instructor should offer relevant scenarios to students, give students time to complete tasks, and find a way to process students' deliberations (SERC 2018). The first step involves what students should do, including informational details relevant to decision-making in the role and a task to complete based on the information. The second involves the actual performing of the task. The document suggests that this could be done individually, in pairs or in groups. The third step is to find a way to assess the students' output. Although there are many benefits to role play as a teaching technique, the facilitator must make sure that all students participate and are truly engaged. Solutions such as awarding grades and making students present to the whole class, or even making students aware that the final examination will include questions pertaining to the role play, are given to counteract the challenge of student apathy.

Budden (2006) provides further benefits of role play and points out that incorporating it into class activities adds variety, a change of pace and provides opportunities for increased language use. He adds that it is a lot of fun and motivating for students. Furthermore, it affords the quieter students the chance to express themselves in a more forthright way (Budden 2006). According to Glover (2014), the world of the classroom is broadened to include the outside world, thus offering a much wider range of language opportunities and providing authentic situations for the students to operate in. The teacher is mainly a facilitator, but can sometimes be a spectator and a participant as the situation demands. The teacher may give students specific instructions or guidance on how to act or what to say (Glover 2014).

Samsibar and Naro (2018) used role play to teach students English conversation and to increase their motivation. They found that there was a significant difference in students' motivation to speak English and concluded that role play was effective in improving students' motivation in English conversation.
The current study used role play together with strategy instruction to provide students with authentic scenarios, to increase their motivation and self-efficacy, and to enable them to engage in reading in a fun way. The study also sought to enable students to actually read their texts and apply deep reading using higher-order thinking and appropriate strategies to achieve comprehension and improve reading proficiency.

\section{Theoretical framework}

The study was based on Guthrie and Wigfield's (2000) engagement framework, which explains that reading comprehension and improved reading proficiency are based on engaged reading. The framework posits that reading is undertaken not because the reader can undertake the activity but because they are motivated to do so (Guthrie \& Wigfield 2000). Thus, if students are motivated to read, they will do so more often and achieve better outcomes. They argue that underlying all reading development is the affective. Thus, reading instruction should be undertaken to improve both cognitive and affective reading levels as the two have a bidirectional relationship (Guthrie \& Wigfield 2000). They recommend that teaching of reading strategies should be undertaken in a way that increases affective attributes, such as reading motivation and self-efficacy.

By developing these affective attributes in conjunction with explicit reading instruction, such as strategy use and vocabulary instruction, a holistic and more intensive development is achieved. Guthrie and Wigfield (2000) further argue that the two-pronged reading instruction approach provides students not only with strategies, but also with affective support, such as self-efficacy and motivation to undertake the reading activity. In addition, the affect also promotes engagement in reading, which is important because it promotes deep reading and thus better comprehension. This resonates with Roberts and Roberts's (2008) argument that the lack of comprehension of sociology texts by students is due to the fact that most students engage in surface reading. They recommend deep reading to promote comprehension, especially with sociology texts. They lament that students' inability to engage in deep reading, leads to their experiencing reading comprehension challenges with texts that require critical thinking for comprehension. An important implication of the framework is that reading interventions should focus on enhancing reading motivation along with reading strategies. Guthrie and his colleagues use concept-oriented reading instruction (CORI) to combine cognitive and affective reading techniques to elicit reading achievement (Guthrie, Taboada \& Coddinton 2007). In this study, role play is combined with explicit strategy instruction to provide a similar effect.

Thus, the use of role play was aimed at motivating the students, enabling them to want to read and to read deeply. For Guthrie and Wigfield's (2000) framework, several teaching guidelines were proposed to improve cognitive and affective reading levels: interesting texts, real-world activities, 
strategy instruction, autonomy, teacher support and collaboration. This study applied strategy instruction and role play, as role play encompasses the majority of the instructional techniques listed in Guthrie and Wigfield's framework, such as autonomy, authenticity, teacher support and collaboration. Role play activities were envisaged to increase students' motivation, while strategy instruction provided competence and built self-efficacy.

\section{Methodology}

The study used both quantitative and qualitative research methodologies and therefore fits into a mixed methods design. Using both quantitative and qualitative methods enabled the researcher to obtain statistical results and verbal data to evaluate the intervention. The verbal data provided more insight into the efficacy of the intervention. According to Creswell and Garrett (2008:321), a mixed methods approach provides greater insight and leads to a better understanding of the research problem. The study also adopted a one-group pre-test-post-test design, which is a quasi-experimental research design in which the same dependent variable is measured in only one group of participants before and after treatment (Axelrod \& Hayward 2017).

\section{Participants}

The participants for the study were first-year Sociology students at a South African university. The students were from different faculties and the majority of them were taking Sociology as an ancillary subject to fulfil a requirement of their respective programmes. The ages of the students were not specifically elicited, but first-year students used in another study at the same institution were between 17 and 21 years (Boakye 2017). The number of students from each faculty were not determined, but the faculties represented are Engineering, Built Environment and Information Technology (EBIT), Economic and Management Sciences (EMS) and Humanities. There were 593 students registered for the first-year Sociology module, but only 366 were involved in the pre-test, 255 in the posttest and 193 in both tests. Since the data were collected during tutorials, only students who attended tutorials during the week of data collection participated. Thus, poor tutorial attendance, attrition rates (as some students drop out of a module before the end of the semester), and other issues may have contributed to the reduced numbers, especially in the post-test.

\section{Instruments}

Two main instruments were used to assess the effect of the combined role play and strategy instruction approach to tutorials. These were the test for academic literacy levels (TALL) to determine the students' pre-test and post-test performance, and a closed-ended and open-ended questionnaire to determine the students' views on the combined approach. The TALL comprised six sections (scrambled text or sequencing, academic vocabulary, graphic and visual information, text types or identification of genres, understanding texts or comprehension, and grammar and text relations) (ICELDA 2017). The TALL is compiled by ICELDA and has been shown to be highly valid and reliable in testing students' academic literacy (Le, Du Plessis \& Weideman 2012). Although the TALL is based on an academic literacy construct, it essentially assesses reading proficiency, as sections such as sequencing, understanding text type, understanding academic vocabulary, understanding texts or comprehension, and grammar and text relations are all reading-oriented.

The questionnaire was adapted from Boakye (2017) to suit the context of the Sociology students. The pre-intervention questionnaire comprised questions on reading self-efficacy (14 questions) and reading strategies (13 questions). The post-intervention questionnaire consisted of 10 self-efficacy questions and nine strategy-use questions in relation to the intervention. Because the post-intervention questions related specifically to the intervention, they were not correlated with the pre-intervention questionnaire and are discussed separately. The open-ended question in the post-intervention questionnaire sought to elicit students' opinions on the intervention.

\section{Procedures and data collection}

Ethical clearance for the study was obtained from the Faculty of Humanities of the institution where the study was conducted. The students completed informed consent forms before they wrote the academic reading and literacy test (TALL) and answered the questionnaire at the beginning of the first semester. The pre-test was written during their lecture time but the questionnaires were answered during tutorials. After the 12-week intervention of 50 min a week, during their last lecture of the semester, the students wrote the post-intervention test and completed the closed-ended and open-ended questionnaire during the last tutorial.

\section{The intervention}

After the pre-test and pre-intervention questionnaire were completed, an intervention was undertaken, which involved teaching students reading strategies using SQ3R (survey, question, read, recall, review). Lau's (2006) characteristics of poor readers, as listed above, were taken into consideration, and strategies taught were aimed at addressing those issues. Reading strategies such as pre-reading, skimming, applying background knowledge to understand what was read, inferencing, predicting, monitoring comprehension, and repairing any misunderstandings were explained to students with some practice exercises using excerpts from texts by Karl Marx, Emily Durkheim and Max Webber. Students were then put into groups of six and given their individual roles by the group leader. The roles consisted of reading assignments: predicting and surveying information, raising questions, dealing with the difficult vocabulary in the text, clarifying by explaining the information in the text, connecting the information to real-life issues, and summarising and 
paraphrasing the information (Stricklin 2011). Students were given a name for each role: Paula the predictor, Quinn the questioner, Clarence the clarifier, Connie the connector, and Sammy the summariser (Stricklin 2011). Vonny vocabulary was included to bring the number of roles to six. Given the importance of providing students with guidelines during role play activities (Erturk 2015; Glover 2014; SERC 2018), the tutors explained and wrote out the roles for the students. For example, for Quinn the questioner guidelines included prompts such as:

I don't understand why ... Why?

How do these two situations compare?

What are the text features telling me?

What is important in this text?

Do I agree with this?

I wonder what will happen if ...?

Were the initial predictions right?

What are the possible problems and what are the possible solutions?

Students playing the role of Quinn the questioner were to raise questions such as those listed above in relation to the text they were asked to read and provide answers in a group discussion during tutorials. As indicated by the SERC (2018) document, role play discussions can be done in pairs or in groups.

In addition to the tutorials, the students attended 2-h lectures twice a week where the lecturers presented and introduced the texts. In such a big group, many students find it difficult to follow the lecture and understand the texts. Reading on their own does not help either, as the majority of students reported in a separate study that they hardly read the texts because they found them difficult and could not understand (Boakye \& Linden 2018; Boakye \& Mai 2016). The tutorials consisted of smaller groups of 25 students each and were managed by postgraduate students as tutors. It is within these tutorials that students are supposed to be assisted and supported for the Sociology module. However, students were not reading the texts because they found them difficult to understand. Thus, the intervention was aimed at assisting and supporting students in reading and understanding the texts, improving their reading proficiency, and enabling them to be successful in the module, and hopefully transfer the skills to other modules. The post-test and post intervention questionnaire data were to determine the effectiveness of the tutorial support.

\section{Data analysis}

The pre-test and post-test results were analysed using paired $t$-test to determine any differences in the students' performance and to answer research question 1 (To what extent will an intervention of reading comprehension strategy instruction through role play improve students' reading of academic texts?). The pre-intervention questionnaire was analysed using descriptive statistics to determine the students' affective reading levels (motivation and self-efficacy) and strategy use. Thereafter, the postintervention questionnaire was analysed using descriptive statistics with Cronbach's alpha to determine the students' responses to the intervention and assess its efficacy. The open-ended questions were analysed using content analysis based on emerging themes. The questionnaire responses were used to answer research question 2 (Will the use of role play in reading comprehension strategy instruction influence students' affective reading levels and strategy use?) and research question 3 (What are students' opinions on the use of role play in a reading comprehension strategy instruction?).

\section{Findings}

Although there was no control group (to allow all the students to benefit from the intervention), the pre-test and post-test results were analysed using paired $t$-test to show any differences and determine to what extent role play and strategy use had influenced students' reading proficiency, if at all.

\section{Test results}

The findings of the test results are presented to give an indication of the students' performance. The results show that, on the whole, the students' performance in the pre-test was at average level (at risk), and below average (extremely at risk) for some sections of the test, whereas the performance increased for the post-test (low risk). The results are interpreted in line with the TALL analysis (UAL 2015). The pre-test and post-test results, with means and standard deviations, are given in Table 1.

The means and standard deviations of the pre-test show that students had challenges with academic vocabulary and understanding text types, as the means for those two sections were lower than other sections: 11.54 out of 20 and 25.71 out of 46 . This indicates that students may be having problems with reading comprehension, as vocabulary and understanding of texts together enable comprehension. The total mean of the pre-test, which was 55.63, and the wide standard deviation of 19.91 also indicate that some students were at a low competency level and may have been experiencing reading comprehension challenges.

The descriptive statistics of the post-test, with means and standard deviations, show that there was some improvement in the students' reading ability. The total mean was 61.15, which is an improvement on the pre-test mean of 55.63. The means for the different sections also showed that there have been improvements in the students' reading ability. Understanding text types and academic vocabulary, which were low in the pre-test, were now above 50\% (12.88 out of 20 and 27.79 out of 46 ) in the post-test.

Although the means show improvement, a paired t-test analysis was performed to determine the statistical significance 
TABLE 1: Pre-test and post-test descriptive statistics.

\begin{tabular}{|c|c|c|c|c|c|c|c|c|c|}
\hline \multirow[t]{2}{*}{ Sections } & & \multicolumn{4}{|c|}{ Pre-test } & \multicolumn{3}{|c|}{ Post-test } & \multirow[t]{2}{*}{ Total marks } \\
\hline & & $N$ & Mean & Standard deviation & Standard error & Mean & Standard deviation & Standard error & \\
\hline Scrambled text & Section 1 & 193 & 3.44 & 1.776 & 0.128 & 3.91 & 1.407 & 0.101 & 5 \\
\hline Academic vocabulary & Section 2 & 193 & 11.37 & 4.725 & 0.340 & 12.88 & 4.438 & 0.319 & 20 \\
\hline Graphic and visual information & Section 3 & 193 & 4.70 & 2.009 & 0.145 & 4.85 & 1.989 & 0.143 & 8 \\
\hline Text type & Section 4 & 193 & 3.62 & 1.482 & 0.107 & 3.96 & 1.305 & 0.094 & 5 \\
\hline Understanding texts & Section 5 & 193 & 25.71 & 11.271 & 0.811 & 27.79 & 10.438 & 0.751 & 46 \\
\hline Grammar and text relations & Section 6 & 193 & 6.80 & 5.044 & 0.363 & 7.75 & 5.258 & 0.378 & 16 \\
\hline All sections & Total & 193 & 55.63 & 19.913 & 1.433 & 61.15 & 18.856 & 1.357 & 100 \\
\hline
\end{tabular}

TABLE 2: Paired t-test analysis of sections in the pre-tests and post-tests.

\begin{tabular}{|c|c|c|c|c|c|c|c|}
\hline Section & Mean & Standard deviation & Standard error mean & $T$ & $d f$ & $p$-value & Cohen's d \\
\hline Section 1 & 0.472 & 1.947 & 0.140 & 3.364 & 192 & 0.001 & 0.242 \\
\hline \multicolumn{8}{|l|}{ Post-test } \\
\hline \multicolumn{8}{|l|}{ Pre-test } \\
\hline Section 2 & 1.513 & 3.667 & 0.264 & 5.731 & 192 & 0.000 & 0.413 \\
\hline \multicolumn{8}{|l|}{ Post-test } \\
\hline \multicolumn{8}{|l|}{ Pre-test } \\
\hline Section 3 & 0.155 & 1.836 & 0.132 & 1.176 & 192 & 0.241 & 0.085 \\
\hline \multicolumn{8}{|l|}{ Post-test } \\
\hline \multicolumn{8}{|l|}{ Pre-test } \\
\hline Section 4 & 0.347 & 1.680 & 0.121 & 2.871 & 192 & 0.005 & 0.207 \\
\hline \multicolumn{8}{|l|}{ Post-test } \\
\hline \multicolumn{8}{|l|}{ Pre-test } \\
\hline Section 5 & 2.083 & 8.031 & 0.578 & 3.603 & 192 & 0.000 & 0.259 \\
\hline \multicolumn{8}{|l|}{ Post-test } \\
\hline Section 6 & 0.948 & 4.372 & 0.315 & 3.013 & 192 & 0.003 & 0.217 \\
\hline \multicolumn{8}{|l|}{ Post-test } \\
\hline \multicolumn{8}{|l|}{ Pre-test } \\
\hline Total & 5.518 & 11.139 & 0.802 & 6.882 & 192 & 0.000 & 0.494 \\
\hline \multicolumn{8}{|l|}{ Post-total } \\
\hline Pre-total & & & & & & & \\
\hline
\end{tabular}

of the improvement. The t-test showed an overall statistically significant improvement at $t=6.85 ; \mathrm{df}=192 ; p<0.05$, specifically at $p<0.0001$. Individually, each section also showed statistically significant improvement, except for section 3 , as shown in Table 2. To determine the magnitude of the statistically significant difference and the extent of the improvement, a Cohen's d was applied to yield effect sizes. Effect size of 0.2 is said to be small, 0.5 medium and 0.8 large (Lakens 2013). The effect sizes for the sections were small, as they were around 0.2. However, the effect size for the overall total showed a higher magnitude above $0.4(t=6.882, \mathrm{df}=192$, $p<0.001$, effect size $=0.494)$. Cohen's d effect size for each section is provided in Table 2 .

The small to medium effect sizes may be due to the short duration of the intervention, as it lasted for only 12 weeks. A longer duration of a year may yield larger effect sizes. A calculation of the correlation coefficient was positive and yielded a large difference (0.836) for the post-test-pre-test total $(r=0.836, p<0.001)$.

Although the means of the pre-tests and post-tests showed improvement, the statistically significant results strengthen the improvement of the students' reading proficiency. This improvement could be attributed to the positive effect of the tutorial approach. However, this outcome is presented with caution as there was no control group. Due to the absence of a control group, the questionnaire was used to corroborate or disprove the test results, and responses from the closedended and open-ended questionnaires confirmed the benefits of the intervention and provided insight into students' improved reading proficiency.

\section{Questionnaire results on strategy use and affective levels}

The closed-ended questionnaire consisted of questions on self-efficacy and motivation (affective) and strategy use (cognitive). Since the questions in the pre-intervention questionnaire were general, but the questions on the postintervention questionnaire were specific to the intervention, they were not directly and analytically compared. The preintervention questionnaire was undertaken to determine the students' level of reading self-efficacy and strategy use, and the post-intervention questionnaire was to determine the effectiveness of the intervention.

There was a total of 366 students for the pre-intervention questionnaires. For the 17 items under self-efficacy and motivation, the Cronbach's alpha was 0.896, which according to Hinton et al. (2004) is considered high reliability. The mean for self-efficacy and motivation was 
3.375, which pointed to low reading self-efficacy and motivation, as the Likert scale questionnaire had 1 for strongly agree and 2 for agree, and therefore any response above 2 was considered negative.

For the section on strategy use, 14 items were analysed. For the 14 items under strategy use, the Cronbach's alpha was 0.746, which was also considered high reliability (Hinton et al. 2004). The mean was 2.229, which pointed to borderline strategy use. Although not as low as their self-efficacy, students' strategy use also needed improvement. In other words, students had low reading proficiency and low affective reading levels before the intervention was conducted.

However, the focus was more on the post-intervention questionnaire, as questions were on the intervention and the responses were to determine the effectiveness of the intervention. The four-point Likert scale was from 1 (strongly agree) to 4 (strongly disagree). A total of 255 students responded to the post-intervention questionnaire. The section on self-efficacy consisted of 10 items with a Cronbach's alpha of 0.787 , which was considered high reliability (Hinton et al. 2004). The overall mean was 2.092 with a standard deviation of 0.447 , indicating a majority agreement. The standard deviation of 0.447 also shows stronger cohesion compared to the standard deviation of the pre-intervention questionnaire, which is 0.645 . The fact that there were virtually no negative responses to the self-efficacy questions in the post-intervention questionnaire indicates that students seemingly had higher self-efficacy, most likely emanating from the intervention, as compared to the means above 3 for the self-efficacy questions in the pre-intervention questionnaire on their general reading self-efficacy.

In relation to strategy use, there were nine items with a Cronbach's alpha of 0.836 . The overall mean was 2.00 , which shows that students agreed with statements without any disagreement. This seems to point to many more students using appropriate strategies, after the intervention. Table 3 shows the differences in means of the pre-intervention and post-intervention questionnaires.

Thus, the closed-ended post-intervention questionnaire also showed positive responses from the students in terms of their strategy use and affective reading (i.e. self-efficacy and motivation). The open-ended responses provided more insight into how the students' reading proficiency improved.

\section{Students' opinions on the use of role play to improve comprehension}

The open-ended questionnaire was to elicit students' opinions on the use of role play and strategy instruction within a reading intervention to improve their reading proficiency. The responses shed further light on the intervention and how the students perceived it. Most of the students reported that the reading intervention improved their reading proficiency. Of the 255 students, 11 did not respond to the open-ended question. Of the 244 who responded, 91\% reported understanding the texts better. Only 9\% reported still having difficulty. Of the $91 \%$ who reported benefits, $38 \%$ specifically mentioned the benefit of the group discussions, which involved the role play, and 35\% specifically mentioned the benefit of the strategy instruction. Although the benefits of the role play and strategy instruction are implied in the benefits of the tutorial activities in terms of improving the students' understanding of the texts and their general reading proficiency, several students directly highlighted the benefits of one or the other. In addition to comments on the role play and strategy use, of the $91 \%$ who made positive comments on the intervention, 35\% specifically mentioned its benefits regarding either self-efficacy or motivation. In other words, these students mentioned an increase in their affective reading levels. Examples of these comments are presented under the following five emerging themes: understanding texts, group discussions (role play), affect (e.g. motivation and self-efficacy), and strategy use. Some examples from the $9 \%$ of the students who expressed having difficulty are also given. The questionnaires were numbered from 1 to 255 and responses are provided according to the questionnaire number.

\section{Understanding texts}

Most of the students reported that the reading intervention had improved their understanding of the texts. According to Stricklin (2011:621), the four strategies of predicting, clarifying, questioning and summarising highly increase comprehension. The following examples show how the students found it easier to understand the sociology concepts, engage in deep reading, increase their vocabulary, and engage in meaningful reading to gain understanding. For example, Respondent 20 reported that she found the concepts easier to understand and could read with more insight and understanding:

'By relating the text to current situations, I gained a better understanding. The tutorial activities enabled me to understand the authors' perspectives. I was able to 'debunk' the texts and put things in my own perspective.' (Respondent 20)

'I was able to read in depth and to understand what Sociology is all about. I can now relate them [the texts] to what is happening in the world, and my vocabulary has also increased. I now have a better understanding of many more words and concepts.' (Respondent 50)

'The activities have been a great help. It helped me to get a deep understanding of Sociology. It also made me want to read more. I can link the information to everyday life to make it more understandable.' (Respondent 127)

TABLE 3: Questionnaire responses.

\begin{tabular}{|c|c|c|c|c|c|c|c|c|c|c|}
\hline \multirow[t]{2}{*}{ Section } & \multicolumn{5}{|c|}{ Pre-intervention } & \multicolumn{5}{|c|}{ Post-intervention } \\
\hline & $N$ & Item & Mean & Standard deviation & Cronbach's alpha & $N$ & Item & Mean & Standard deviation & Cronbach's alpha \\
\hline Reading self-efficacy & 366 & 17 & 3.375 & 0.645 & 0.896 & 255 & 10 & 2.092 & 0.447 & 0.787 \\
\hline Reading strategies & 366 & 14 & 2.229 & 0.493 & 0.743 & 255 & 9 & 2.00 & 0.501 & 0.836 \\
\hline
\end{tabular}


'I learnt to read in greater detail, identify arguments, as well as contextualise the information.' (Respondent 147)

'It has improved my vocabulary; now when I read the articles, I read to understand the deeper meaning.' (Respondent 201)

\section{Strategy use}

The students' responses to the explicit teaching of strategies, such as pre-reading, predicting, application of background knowledge and identification of main and supporting ideas are given below. Respondent 9 reported that she obtained a better understanding because she was able to form visual images, which helped improve her reading ability:

'I learnt how to extract main ideas from the texts and I am able to visualize the texts I read and to focus on the main concepts.' (Respondent 9)

'I now try to find the main ideas in order to understand the texts. I found it easier to summarize the texts because I knew what to look for.' (Respondent 12)

'The reading strategies we were taught helped break down the article into sections and that helps when studying.' (Respondent 41)

'I could easily identify main ideas and important concepts and to summarise the texts using the reading strategies.' (Respondent 48)

'Tutorials provided me with tips [strategies] on how to read the texts and this helped me understand the texts better and engage in discussions.' (Respondent 66)

\section{Group discussions and role play activities}

Although the students' responses sometimes straddle the various sections, the following excerpts were extracted for role play and the related group discussions. The students reported that the role play activities compelled them to read the texts and participate in discussions:

'The discussions helped me to understand concepts, because I was forced to look up new words. They helped me understand Sociology, because they made me read more.' (Respondent 156)

'The tutorials had a great impact on my reading of the Sociology articles because I could engage in the discussions in my role.' (Respondent 157)

'The discussions made me to think more critically and not to look at things at face value. The summaries provided by the summariser in the group made it easier when reading the actual text.' (Respondent 177)

'Making contributions to the group helped to make my own ideas when writing. The roles of my peers also helped to explain some of the parts of the article that I did not understand.' (Respondent 189)

'Because I had to contribute in my role, it made me read the texts rather than waiting until tests or exams.' (Respondent 204)

\section{Affective reading aspects of motivation and self-efficacy}

Students' responses also reflected increased motivation and self-efficacy levels. These affective aspects influence strategy use and overall reading proficiency. Examples of the affective responses are given below to indicate the benefits of the role play strategy instruction. Students reported increased motivation and believed in their ability to read successfully as a result of the role play activities.

\section{Motivation}

'The roles I played motivated me to read and they made me more interested.' (Respondent 31)

'I was motivated to read because I have to do the assignments and prepare for the discussions.' (Respondent 45)

'It was interesting to read and relate the information to real life so I read them.' (Respondent 80)

'The discussions and the activities during tutorials helped me to read better, and made me want to read more.' (Respondent 95)

'The tutorials were interesting and fun and motivated me to read the Sociology articles.' (Respondent 108)

'The tutorial activities have been a great help. They helped me to get a deep understanding of Sociology. It also made me want to read more. I was motivated to read frequently, and not leave reading till exam time.' (Respondent 127)

\section{Self-efficacy}

'I am able to understand what I read better. And it has increased my ability to understand what Sociology is about.' (Respondent 46)

'I am more confident about my ability to read and to be able to answer questions. I can also relate the information in the article to what is happening in the world. My vocabulary has improved greatly and I understand most of the words and concepts in the articles.' (Respondent 51)

'I can understand difficult concepts and want to read the prescribed work. I am able to relate whatever I'm reading with my own ideas.' (Respondent 89)

'I am able to identify the main points in the articles, and explain and give my own examples.' (Respondent 135)

Despite the positive outcomes of the combined approach to improve reading proficiency within tutorials, a few students $(9 \%)$ still had challenges with reading their assigned work. Some of these students stated: 'I don't understand what I read sometimes', 'the length of the Sociology articles made me struggle to get the main ideas', 'the tutorials and the activities did not assist me' and 'I still struggle and still need help with my work'.

The insights gained from the open-ended questionnaire responses showed that the students, on the whole, were positive about the combined approach of role play and strategy instruction. In other words, not only did the students report that they benefited from the strategy instruction by using appropriate strategies for comprehension, but the role play had also enabled them to learn from their peers, engage in deep reading, improve their affective reading levels (motivation and self-efficacy), develop independent reading and gain better understanding.

\section{Discussion}

The three data sets consisting of tests, a closed-ended questionnaire, and an open-ended questionnaire all indicated positive outcomes of the intervention. The descriptive statistics 
of the pre-test and post-test results showed that the students' reading proficiency had improved. Furthermore, the improvement was statistically significant with small to medium effect sizes. Although there was no control, the questionnaire responses confirm the benefits in that only a few students $(9 \%)$ reported experiencing challenges after the intervention. A majority of the students had positive comments, which indicated improved reading comprehension, vocabulary and strategy use, as well as higher levels of motivation and self-efficacy. According to Stricklin (2011), the strategies of predicting, clarifying, questioning and summarising increase comprehension. Students had increased their understanding of the articles, which were hitherto challenging for them. In addition, some of the students reported that understanding the texts made them read more frequently, which ultimately increased their motivation and improved their comprehension (Grabe \& Stoller 2011). Furthermore, because they had to prepare for the role play discussions, they could not come to class without having read the texts. The roles they had to play, in a sense, compelled them to read. They also found the role play discussions to be fun, confirming Budden's (2006) assertion that role play is fun and motivating for students. A number of students commented on being able to relate the texts to real life, which helped to improve comprehension and make the text more meaningful. According to the SERC (2018) document, an advantage of role play is that it allows students to apply content in a relevant and real-world context. For example, the character of Connie the connector made connections between the information in the text and real-life situations, and highlighted these connections during the class discussions. Glover (2014) explains that by providing students with authentic situations to operate in, role play improves learning. Guthrie and Wigfield's (2000) engagement framework explains that the use of authentic texts and authentic situations provides a basis for engagement in reading, which promotes comprehension. Students applied reading strategies in authentic ways, as the texts used for the intervention were the same texts on which they would be assessed in the Sociology module.

Glover (2014) points out that if students have a form of evaluation attached to the role play, they gain more from it. Because the texts used for the intervention were the same texts used for the Sociology module, the students were eager to engage with the texts and perform their assigned roles.

The role play also encouraged deep reading: a number of students reported reading deeply in order to perform their roles. This confirms and aligns with the benefits of role play and engaged reading that emanates from the affective and cognitive benefits thereof (Glover 2014; Guthrie \& Wigfield 2000; SERC 2018). In other words, deep reading, or engaged reading, which can only be attained if appropriate strategies are used in a motivating way (Guthrie \& Wigfield 2000), had been attained by a number of students. Guthrie and Wigfield (2000) argue that engaged readers are proficient and strategic readers. Thus, when students read deeply, they are engaged and use appropriate strategies to obtain meaning, thereby improving their reading comprehension.

Finally, a number of students reported increased and improved vocabulary use. According to Glover (2014) and Budden (2006), the world of the classroom is broadened to include the outside world during role play, thus offering a much wider range of language opportunities, increased vocabulary and improved reading proficiency.

\section{Limitation}

Although the study has reported on the benefits of a combined approach of role play and strategy instruction in improving reading comprehension and reading proficiency, the findings should be considered within the limitations of the study. In addition to the challenges of a quasi-experimental design in educational research, the study had no control group. Although this is acceptable in quasi-experimental studies in cases where it is not feasible, it limits the research findings. However, this limitation was counteracted by having three data sets to compare. A similar study with a control group would strengthen the findings of this study.

\section{Conclusion}

Using three data sets to determine the efficacy of the intervention, this study has shown that an approach of using role play within strategy instruction can help to improve reading comprehension. The pre-test and posttest results showed statistically significant improvement in students' reading performance, which could be attributed to the intervention. The closed-ended and opened-ended questionnaire data corroborated the results of the post-test, with a majority of the students reporting improvements in their self-efficacy, their strategy use and, most importantly, their understanding of the texts. The approach seems to have contributed to an increase in students' use of appropriate strategies, which helped to improve their reading comprehension. The role play provided an affective stance that promoted deep reading and independent reading that also contributed to deeper understanding and increased vocabulary. Furthermore, the attainment of comprehension cultivated in the students a desire to read more. It also increased their affective reading levels, which is important for engaged and deep reading. The students reported increased motivation to read and higher reading self-efficacy. However, the test results should be interpreted with caution, as the study was a one-group pre-post-test design without a control group. This article contributes to research on reading development at tertiary level and responds to the call to find innovative ways to improve students' academic reading comprehension for better academic performance.

\section{Acknowledgements}

Mr Andries Masenge and Dr Andre du Plessis from the statistics department who helped with the analysis of data. 


\section{Competing interests}

The author has declared that no competing interest exists.

\section{Author's contributions}

I declare that I am the sole author of this research article.

\section{Ethical considerations}

Ethical clearance for the study was obtained from the Faculty of Humanities, University of Pretoria.

\section{Funding information}

The research was supported by the CSUR grant from the NRF.

\section{Data availability}

Data sharing is not applicable to this article as no new data were created or analysed in this study.

\section{Disclaimer}

The views and opinions expressed in this article are those of the author and do not necessarily reflect the official policy or position of any affiliated agency of the author.

\section{References}

Aghaie, R. \& Zhang, L.J., 2012, 'Effects of explicit instruction in cognitive and metacognitive reading strategies on Iranian EFL students' reading performance and strategy transfer', Instructional Science 40, 1063-1081. https://doi. and strategy transfer', Instructior
org/10.1007/s11251-011-9202-5

Alderson, J.C., 2000, Assessing reading, Cambridge University Press, Cambridge.

Anderson, N.J., 1991, 'Individual differences in strategy use in second language reading and testing', Modern Language Journal 75(4), 460-472. https://doi. org/10.1111/j.1540-4781.1991.tb05384.x

Axelrod, D.M. \& Hayward, R., 2017, 'Nonrandomized interventional study designs (quasi-experimental designs)', in D.F. Penson \& J.T. Wei (eds.), Clinical research for surgeons, pp. 63-76, Humana Press Inc., Totowa, NJ, viewed from http://eknygos. Ismuni.lt/springer/587/63-76.pdf.

Barber, A.T. \& Klauda, S.L., 2020, 'How reading motivation and engagement enable reading achievement: policy implications', Policy Insights from the Behavioral and Brain Sciences 7(1), 27-34. https://doi.org/10.1177/ 2372732219893385

Boakye, N., 2015, 'The social dimension of reading literacy development in South Africa: Bridging inequalities among the various language groups', Internationa Journal of the Sociology of Language 234, 133-156. https://doi.org/10.1515/ijsl2015-0008

Boakye, N.A., 2017, 'Efficacy of a reading intervention for first-year university students', Per Linguam 33(1), 1-24.

Boakye, N.A.Y. \& Linden, M-L., 2018, 'Extended strategy-use instruction to improve students' reading proficiency in a content subject', Reading \& Writing 9(1). https://doi.org/10.4102/rw.v9i1.212

Boakye, N.A.N.Y. \& Mai, M.M., 2016, 'A needs analysis for a discipline-specific reading intervention', English Language Teaching 9(3), 235-247.

Boakye, N., Sommerville, J. \& Debusho, L., 2014, 'The relationship between socioaffective factors and reading ability: Implications for tertiary reading instruction', Journal for Language Teaching 48(1), 173-213.

Brown, H.D., 2001, Teaching by principles: An interactive approach to language pedagogy, Prentice Hall Regents, Englewood Cliffs, NJ.

Brown, H.D., 2007, Principles of language learning and teaching, Pearson Education, White Plains, NY.

Bruen, J., 2017, 'Language learning strategies for reading comprehension: Assessing the strategy use of young adults at beginners' level taking Chinese, German, Japanese or Spanish as foreign languages at university', Language Learning Journal 45(2), 170-186. https://doi.org/10.1080/09571736.2017.13 70606

Budden, J., 2006, 'Role-play', British Council training resource, viewed 20 August 2020 from https://www.teachingenglish.org.uk/article/role-play.
Chamot, A.U., 2005, 'Language learning strategy instruction: Current issues and research', Annual Review of Applied Linguistics 25, 112-130. https://doi. research, Annual Review of Appli
org/10.1017/S0267190505000061

Chesler, M. \& Fox, R., 1966, Role-playing methods in the classroom, Science Research Associates, Inc., Chicago, IL.

Cohen, A.D., 2011, 'Second language learner strategies', in E. Hinkle (ed.), Handbook of research in second language teaching and learning, vol. 2, pp. 681-698, Routledge, New York, NY.

Creswell, J.W. \& Garrett, A.L., 2008, 'The "movement" of mixed methods research and the role of educators', South African Journal of Education 28, 321-333. https:// doi.org/10.15700/saje.v28n3a176

Eghlidi, M., Abdorrahimzadeh, S.J. \& Sorahi, M.A., 2014, 'Metacognitive online reading strategies among graduate students: Does the proficiency level make a difference?', Modern Journal of Language Teaching Methods 4(4), 57-70.

Erturk, E., 2015, 'Role play as a teaching strategy', Conference paper presented at the National Tertiary Learning and Teaching Conference in Tauranga. https://doi. org/10.13140/RG.2.1.4287.9449

Ferrara, S.L.N., 2005, 'Reading fluency and self-efficacy: A case study', Internationa Journal of Disability, Development and Education 52(3), 215-231. https://doi. org/10.1080/10349120500252858

Glover, I., 2014, 'Role-play: An approach to teaching and learning', viewed 20 August 2020, from https://blogs.shu.ac.uk/shutel/2014/07/04/role-play-an-approachto-teaching-and-learning/.

Grabe, W., 2008, Reading in a second language: Moving from theory to practice, Cambridge University Press, Cambridge.

Grabe, W. \& Stoller, F., 2011, Teaching and researching reading, Longman/Pearson.

Graesser, A.C., 2007, 'An introduction to strategic reading comprehension', in D.S. McNamara (ed.), Reading comprehension strategies: Theories, Interventions, and Technologies, pp. 3-26, Psychology Press, Hove.

Guthrie, J.T., 2008, 'Reading motivation and engagement in middle and high school: Appraisal and intervention', in J.T. Guthrie (ed.), Engaging adolescents in reading, pp. 1-16, Corwin Press, Thousand Oaks, CA.

Guthrie, J.T., Taboada, A. \& Coddington, C.S., 2007, 'Engagement practices for strategy learning in concept-oriented reading instruction', in D.S. McNamara (ed.), Reading comprehension strategies: Theories, Interventions, and Technologies, pp. 3-26, comprehension strategies:
Psychology Press, Hove.

Guthrie, J.T. \& Wigfield, A., 2000, 'Engagement and motivation in reading', in M.L. Karmil, P.B. Mosenthal, P.D. Pearson \& R. Barr (eds.), The handbook of reading research, vol. III, pp. 403-420, Lawrence Erlbaum Associates, Mahwah, NJ.

Guthrie, J.T., Wigfield, A. \& You, W., 2012, 'Instructional contexts for engagement and achievement in reading', in S.J. Christenson, A.L. Reschly \& C. Wylie (Eds.), Handbook of research on student engagement, pp. 601-634, Springer, New York.

He, T., 2008, 'Reading for different goals: The interplay of EFL college students' multiple goals, reading strategy use and reading comprehension', Journal of Research in Reading 31(2), 224-242. https://doi.org/10.1111/j.1467-9817. 2007.00355.x

Hinton, P.R., Brownlow, C., McMurray, I. \& Cozens, B., 2004, SPSS Explained, Routledge, London.

Ilustre, C.A.P., 2011, 'Beliefs about reading, metacognitive reading strategies and text comprehension among college students in a private university', Philippine ESL Journal 7, 28-47.

Inter-institutional Centre for Language Development and Assessment (ICELDA), 2017 Sample test, viewed 20 August 2020, from https://icelda.com/wp-content/ uploads/2019/07/TALL.pdf.

Jacobs, C., 2007, 'Towards a critical understanding of the teaching of disciplinespecific academic literacies: Making the tacit explicit', Journal of Education 41(1), 59-81.

Karami, H., 2008, Reading strategies: What are they?, University of Tehran, viewed 20 August 2020, from https://files.eric.ed.gov/fulltext/ED502937.pdf.

Lakens, D., 2013, 'Calculating and reporting effect sizes to facilitate cumulative science: A practical primer for $t$-tests and ANOVAs', Frontiers in Psychology 4(863). https://doi.org/10.3389/fpsyg.2013.00863

Lau, K., 2006, 'Reading strategy use between Chinese good and poor readers: A thinkaloud study', Journal of Research in Reading 29(4), 383-399. https://doi. org/10.1111/j.1467-9817.2006.00302.x

Le, P.L., Du Plessis, C. \& Weideman, A., 2012, 'Test and context: The use of the test of academic literacy levels (TALL) at a tertiary institution in VIÊT NAM', Journal for Language Teaching 45(2), 115-131. http://doi.org/10.4314/jlt.v45i2.7

McNamara, D.S. (Ed.), 2007, Reading comprehension strategies: Theories, interventions, and technologies, Lawrence Erlbaum Associates Publishers, Mahwah, NJ.

Mokhtari, K. \& Sheorey, R., 2002, 'Measuring ESL students' awareness of reading strategies', Journal of Developmental Education 25, 2-10.

Moransky-Miller, M., 2010, 'Cognitive and affective reading development during an after school program: A case study of three adolescent readers' participation in the program', unpublished doctoral thesis, Kent State University Graduate School of Education, Kent.

Organisation for Economic Co-operation and Development, 2010, PISA 2009 results: Learning to learn-Student engagement, strategies and practices, Vol. III, OECD, Paris. https://doi.org/10.1787/9789264083943-en

Oxford, R., 1990, Language learning strategies: What every teacher should know, Heinle and Heinle, Boston, MA. 
Oxford, R., 2011, Teaching and researching language learning strategies, Pearson Education, Harlow.

Pani, S., 2004, 'Reading strategy instruction through mental modelling', ELT Journa 58(4), 355-362. https://doi.org/10.1093/elt/58.4.355

Pretorius, E.J., 2000, 'Inference generation in the reading of expository texts by university students', unpublished doctoral thesis, University of South Africa, Pretoria.

Roberts, K.A. \& Roberts, C., 2008, 'Deep reading, cost/benefit, and the construction of meaning: Enhancing reading comprehension and deep learning in sociology courses', Teaching Sociology 36(2), 125-140. https://doi.org/10.1177/ $0092055 \times 0803600203$

Samsibar, S. \& Naro, W., 2018, 'The effectiveness of role play method toward students' motivation in English conversation', Eternal: English, Teaching Learning and Research Journal 4(1), 107-115. https://doi.org/10.24252/Eternal. V41.2018.A8

Schiefele, U., Schaffner, E., Moller, J. \& Wigfield, A., 2012, 'Dimensions of reading motivation and their relation to reading behaviour and competence', Reading Research Quarterly 47, 427-463. https://doi.org/10.1002/RRQ.030

Science and Engineering Research Council (SERC), 2018, Role playing, viewed September 2020, from https://serc.carleton.edu/introgeo/interactive/roleplay. htm

Stricklin, K., 2011, 'Hands-on reciprocal teaching: A comprehension technique', The Reading Researcher 64(8), 620-625. https://doi.org/10.1598/RT.64.8.8
Suobere, P.T. \& Eniekenemi, E., 2017, 'Role playing teaching strategy and its effect on academic Achievement of students in learning simple blue print reading',
International Journal of Innovative Social \& Science Education Research 5(4), 50-55.

Taylor, S. \& Yu, D., 2009, 'Socio-economic status and educational achievement: Does education provide a stepping stone out of poverty in South Africa?', Transformation Audit 2009, 66-75.

Tse, S.K. \& Xiao, X., 2014, 'Differential influences of affective factors and contextual factors on high-proficiency readers and low-proficiency readers: A multileve analysis of PIRLS data from Hong Kong', Large-scale Assessments in Education 2, 6. https://doi.org/10.1186/s40536-014-0006-3

Unit for Academic Literacy (UAL), 2015, TALL results analysis, University of Pretoria, Pretoria.

Wigfield, A., Mason-Singh, A., Ho, A.N. \& Guthrie, J.T., 2014, 'Intervening to improve children's reading motivation and comprehension: Concept-oriented reading
instruction', in A. Wigfield, A. Mason-Singh A., A.N. Ho \& J.T. Guthrie (eds.), Motivational interventions, pp. 37-70, Emerald Group Publishing Limited, Bingley. https://doi.org/10.1108/S0749-742320140000018001

Wright, M. \& Brown, P., 2006, 'Reading in a modern foreign language: Exploring the potential benefits of reading strategy instruction', Language Learning Journal 33(1), 22-33. https://doi.org/10.1080/09571730685200071

Yang,G., Badri, M., Asma Al Rashedi, A.A. and Karima Almazroui, K., 2018, The role of reading motivation, self-efficacy, and home influence in students' literacy achievement: a preliminary examination of fourth graders in Abu Dhabi, Large-scale Assessments in Education, 6(10), 1-19. https://doi.org/10.1186/s40536-018-0063-0 